\title{
DIFFERENTIATION BETWEEN DECOMPOSED REMAINS OF HUMAN ORIGIN AND BIGGER MAMMALS
}

\section{ABSTRACT}

This study is a follow-up study in the search for a human specific marker in the decomposition where the VOC-profile of decomposing human, pig, lamb and roe remains were analyzed using a thermal desorber combined with a gas chromatograph coupled to a mass spectrometer in a laboratory environment during 6 months. The combination of 8 previously identified human and pig specific compounds (ethyl propionate, propyl propionate, propyl butyrate, ethyl pentanoate, 3-methylthio-1propanol, methyl(methylthio)ethyl disulfide, diethyl disulfide and pyridine) was also seen in these analyzed mammals. However, combined with 5 additional compounds (hexane, heptane, octane, N-(3methylbutyl)- and N-(2-methylpropyl)acetamide) human remains could be separated from pig, lamb and roe remains. Based on a higher number of remains analyzed, as compared with the pilot study, it was no longer possible to rely on the 5 previously proposed esters to separate pig from human remains. From this follow-up study reported, it was found that pyridine is an interesting compound specific to human remains. Such a human specific marker can help in the training of cadaver dogs or in the development of devices to search for human remains. However, further investigations have to verify these results.

\section{KEYWORDS}

TD-GC/MS; decomposition; human specific marker; volatile organic compounds 


\section{INTRODUCTION}

A multidisciplinary approach is used in the search of human bodies and remains. With manual probing, a probe is used to find differences in the density of soil; thermal imaging can be used to search for increased microbial activity; ground penetrating radars use electromagnetic waves; and cadaver dogs can be trained to search for volatiles that smell like death. All these techniques have one disadvantage in common: they are not specific for human remains. ${ }^{1-3}$

Pig remains are known to be similar to human remains not only in weight, fat-to-muscle ratio or hair coverage $^{2,4,5}$ but also the profile of volatile organic compounds (VOCs) released from decomposed pig and human remains are comparable. ${ }^{6}$ Therefore, pig remains are used as human analogues in decomposition studies. 4, 7-9 There are only a few research groups that compared the VOC-profile of human and pig remains. Vass found that carbon tetrachloride, pentane, decane and undecane were human specific and 3-methylbutanal was more abundant than 2-methylbutanal in human remains. ${ }^{10}$ Styrene and methyl benzoate were identified as human specific compounds by DeGreeff et al.. ${ }^{11}$ Cablk et al. compared literature results of human remains with their experimental results of pig remains and others. They identified 11 compounds specific for human remains. ${ }^{12}$

Cadaver dogs can be trained with human tissue collected during an autopsy, (clothes soaked in) decomposition fluids or blood. However, access to these training aids is limited due to ethical and legal issues. Therefore, it can be very useful to use a synthetic mixture. Unfortunately, the synthetic training aids available nowadays are not specific for human decomposition. By searching human specific VOCs, dog training can be more specific using synthetic training aids. ${ }^{1,13}$

In the first paper, Rosier et al. identified VOCs released from 6 decomposing human (numbered as $\mathrm{H} \mathrm{a}$ to $\mathrm{H}$ f) and 26 decomposing animal remains (mammals, fish, birds, amphibians and reptiles) in a laboratory environment using a thermal desorber coupled to a gas chromatograph combined with a mass spectrometer (TD-GC/MS). Among 452 compounds, a collection of 8 compounds was proposed as a human and pig specific combination based on principal component analysis (PCA). This combination comprised of four esters (ethyl propionate, propyl propionate, propyl butyrate and ethyl pentanoate), three sulfur-containing compounds (diethyl disulfide, methyl(methylthio)ethyl disulfide and 3-methylthio-1-propanol) and a nitrogen-containing compound (pyridine). Pig remains were separated from human remains based on a combination of 5 esters (3-methylbutyl pentanoate, 3-methylbutyl 3- 
methylbutyrate, 3-methylbutyl 2-methylbutyrate, butyl pentanoate and propyl hexanoate). However, only one pig was used in the study and further investigation had to corroborate these results. There was also lack of other bigger animals in this study. ${ }^{6}$ Defining (a) human specific marker(s) can overcome the disadvantage of the techniques that are used nowadays to locate human remains. Cadaver dogs can be trained more efficiently or devices can be developed to search for human specific VOCs.

In this study, the headspace of decomposed human, pig, lamb and roe remains were sampled in a laboratory environment. The samples were collected for six months and analyzed using a TD-GC/MSmethod. PCA was conducted on the identified VOC-profiles. The goal was to corroborate the results from the first paper ${ }^{6}$ by relying on the analyses of 12 new remains: (1) Are the 8 proposed human specific markers visible in additional human remains? (2) Are the 5 esters pig specific as suggested in the first paper? (3) Can human remains be separated from pigs and other bigger mammals (lambs and roe)? 


\section{MATERIALS AND METHODS}

\section{$\underline{\text { Setup of experiment }}$}

Parts of fat tissue, muscle, liver and intestines of 4 pigs ( $P$ a-d), 1 roe, 2 lambs ( $L$ a-b) and 5 human remains $(\mathrm{H} \mathrm{g-k})$ were used in this study. These remains were allowed to decompose in glass jars $(1,062$ L; Covera Packaging NV, Hoboken, Belgium) in a laboratory environment during six months. An empty glass jar was used as blank. The human remains were collected during autopsies by The Institute of Forensic Medicine, University Hospital of Leuven, Belgium. Full approval was received from the Medical Ethics Committee of the faculty of Medicine of the University Hospital of Leuven, Belgium. For the animal remains, an approval was received from the Ethical Committee of the University of Leuven, Belgium.

\section{Sampling and analysis method}

An ACTI-VOC pump (Markes, Frankfurt, Germany) was used to guide the headspace through sorbent tubes (prepacked Tenax TA tubes; 200 mg, $89 \mathrm{~mm}$ x $6.4 \mathrm{~mm}$ o.d.; Camsco, Houston, USA) at a flow of $100 \mathrm{~mL} / \mathrm{min}$ for $20 \mathrm{~min}$. The air was sampled twice a week for the first month, once a week for the following three months and once a month until the remains decomposed for six months. Prior to the sampling, the sorbent tubes were conditioned for $1 \mathrm{~h}$ at $320^{\circ} \mathrm{C}$ with a flow rate of $100 \mathrm{~mL} / \mathrm{min}$ helium (Praxair, Schoten, Belgium). The VOCs on the sorbent tubes were analyzed using a TD-GC/MS (Turbomatrix 150: Perkin Elmer, Zaventem, Belgium; 6890N-GC and 5975B-MS: Agilent Technologies, Diegem, Belgium). Using the TD, the VOCs were desorbed from the tubes at a temperature of $300^{\circ} \mathrm{C}$ for $30 \mathrm{~min}$. The VOCs were collected on a cold trap (coated with Tenax, held at $0{ }^{\circ} \mathrm{C}$ ) using a flow of 40 $\mathrm{mL} / \mathrm{min}$ helium. In the secondary desorption, the trap is heated to $250{ }^{\circ} \mathrm{C}$ at a rate of $99{ }^{\circ} \mathrm{C} / \mathrm{sec}$ and the VOCs are transported on the GC-column (VF-625ms, $60 \mathrm{~m} \times 0.25 \mathrm{~mm} \times 1.4 \mu \mathrm{m})$ via a heated transfer line $\left(250^{\circ} \mathrm{C}\right)$. The GC-oven was held at $40^{\circ} \mathrm{C}$ for $1 \mathrm{~min}$, then increased to $80^{\circ} \mathrm{C}$ at a rate ${ }^{\circ} \mathrm{C} / \mathrm{min}$, further to $120^{\circ} \mathrm{C}$ at a rate of $3{ }^{\circ} \mathrm{C} / \mathrm{min}$ and to $250{ }^{\circ} \mathrm{C}$ at a rate of $5{ }^{\circ} \mathrm{C} / \mathrm{min}$. This temperature was maintained for 10 min with a total GC-runtime of 90.33 minutes. Helium was used as carrier gas at a constant pressure of $29 \mathrm{psi}$. The GC/MS interface was kept at a temperature of $280^{\circ} \mathrm{C}$. The electron impact ion source was used in positive mode at a temperature of $230^{\circ} \mathrm{C}$. The quadrupole mass analyzer was kept at $150^{\circ} \mathrm{C}$. Full scan (FS) spectra were recorded in a mass range of $15-400$ amu and selected ion monitoring (SIM) mode was used to search for the proposed human and pig specific compounds (Table 1). 3-methylbutyl 2-methyl butyrate and 3-methylbutyl pentanoate were not incorporated in the 
SIM-method since no standard was commercially available and the spectra and retention time were very similar to 3-methylbutyl 3-methylbutyrate. The spectra were compared with NIST98 mass spectral library (match factor minimum 70\%).

Table 1: SIM-ions of suggested human and pig specific compounds.

\begin{tabular}{|c|c|c|c|c|c|}
\hline Compound & SIM 1 & SIM 2 & SIM 3 & SIM 4 & SIM 5 \\
\hline \multicolumn{6}{|c|}{ SUGGESTED HUMAN AND PIG SPECIFIC COMPOUNDS } \\
\hline Ethyl propionate & 57 & 74 & 75 & 102 & \\
\hline Pyridine & 52 & 78 & 79 & 80 & \\
\hline Propyl propionate & 57 & 75 & 87 & & \\
\hline Propyl butyrate & 71 & 89 & 101 & 102 & \\
\hline Ethyl pentanoate & 85 & 88 & 101 & 103 & \\
\hline Diethyl disulfide & 66 & 94 & 122 & 124 & \\
\hline 3-methylthio-1-propanol & 61 & 73 & 88 & 106 & 108 \\
\hline Methyl(methylthio)ethyl disulfide & 59 & 75 & 79 & & \\
\hline \multicolumn{6}{|c|}{ SUGGESTED PIG SPECIFIC COMPOUNDS } \\
\hline Butyl pentanoate & 73 & 85 & 103 & & \\
\hline Propyl hexanoate & 99 & 102 & 117 & & \\
\hline 3-methylbutyl 3-methylbutyrate & 70 & 85 & 103 & 129 & \\
\hline
\end{tabular}

\section{$\underline{\text { Data-analysis }}$}

To distinguish the human specific VOCs from less specific VOCs, PCA was conducted on the data using The Unscrambler X (CAMO Software, Oslo, Norway). PCA is a multivariate analysis that is used when dimensionality of the data is high and possibility of replication is low. ${ }^{8}$ The identified compounds were collected in spreadsheets for every sample and species. In full scan mode, the blank was also analyzed as a species. In SIM mode, the identified compounds of the blank were subtracted from the samples. The data were analyzed after six months of decomposition in the same way as done in Rosier et al. 6 . A PCA was also conducted for the possible human and pig specific compounds analyzed in SIM mode when data in SIM mode were available if not; data from FS mode were used. $\mathrm{H} \mathrm{g}, \mathrm{H} \mathrm{h}$ and Roe were only analyzed in SIM mode from day 187, 169 and 18 respectively; these three jars were not analyzed from the start of the decomposition with the SIM-method but were added afterwards because of their importance in the study. 


\section{RESULTS}

\section{General observations}

After six months of decomposition 22-25 samples were taken from every jar. In all the samples, 282 different VOCs were identified. They were classified by chemical class (in parenthesis, the number of identified VOCs is indicated): alkanes (10), alkenes (14), aromatic compounds (10), cyclic compounds (8), ethers (9), alcohols (29), ketones (27), aldehydes (17), acids (9), esters (58), sulfur-containing compounds (53), nitrogen-containing compounds (29), halogen-containing compounds (4) and other compounds (5).

\section{Separation of human remains and other mammals in full scan mode}

Only for alkanes and nitrogen-containing compounds a clear separation was seen in the score-plot of the PCA conducted on the prevalence of the compounds within a chemical class.

Alkanes. In Fig. 1, the human remains are completely separated from the other mammals and the blank. This separation was seen due to the higher frequencies of hexane, heptane and octane: higher than 75 \% (except for heptane in $\mathrm{H} \mathrm{k}(56.52 \%)$ and octane in $\mathrm{H} \mathrm{i}$ and $\mathrm{H} \mathrm{k}(45.45$ and $4.35 \%)$ ). In the roe, pig and lamb remains, these alkanes were identified in $4-50 \%$ of the samples (except for hexane in $\mathrm{P} \mathrm{b}$ $(54.17 \%)$ and octane in $\mathrm{L}$ a $(70.83 \%))$. 

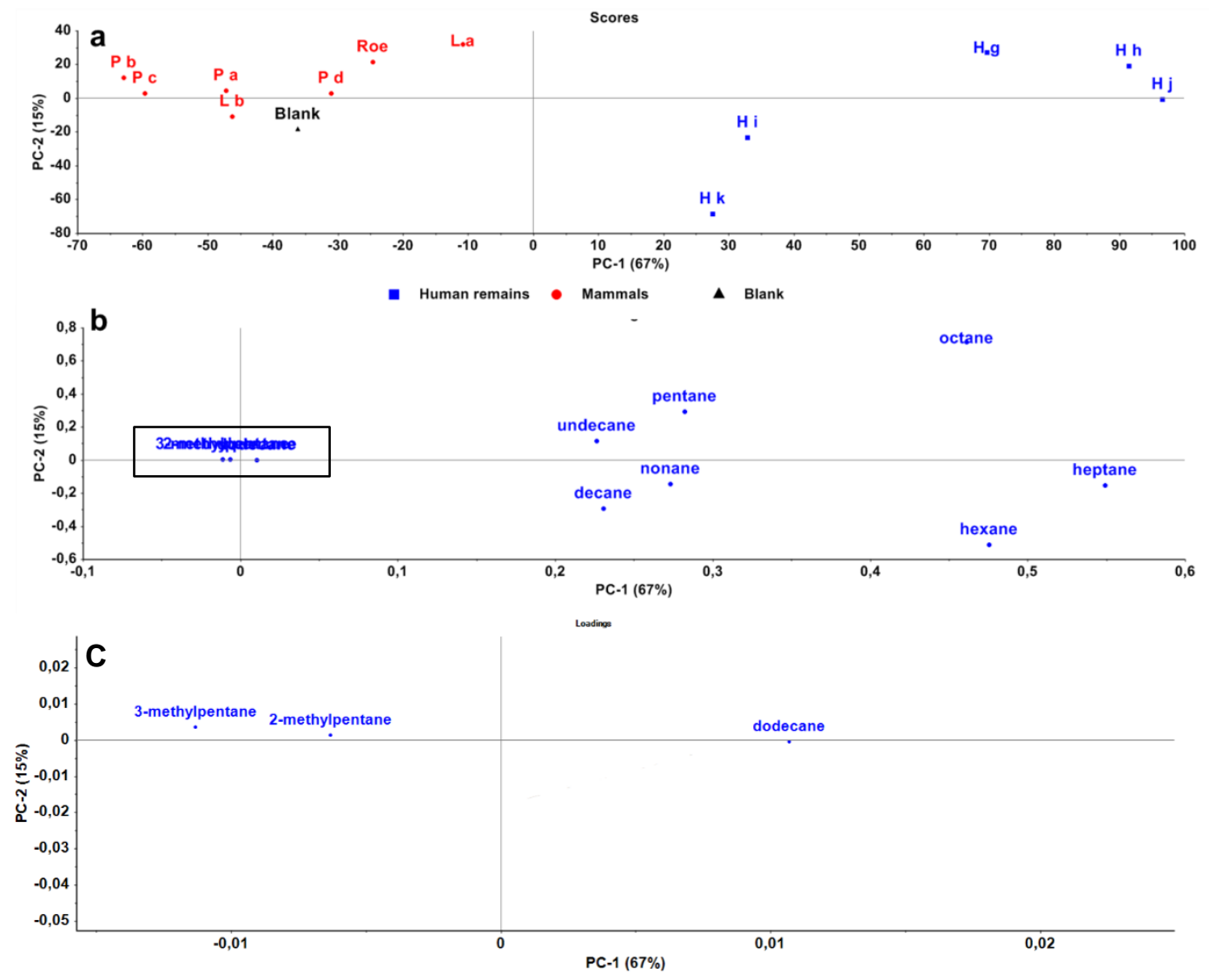

Figure 1: Score- (a) and loading-plot (b) of alkanes and (c) square in detail.

Nitrogen-containing compounds. The human remains are situated on the left of the score-plot (Fig. 2). In the loading-plot, pyridine, $\mathrm{N}$-(2-methylbutyl)acetamide and N-(3-methylbutyl)acetamide are found on the left part of the plot. In the human remains, pyridine was identified in more than $90 \%$ of the samples (except for $\mathrm{H}$ h, only $52 \%$ ). In the other animals, pyridine was found only once in $\mathrm{P} b-\mathrm{d}, \mathrm{L} b$ and the blank. These acetamides were only detected in the human remains (more than $59.09 \%$ ) except for $\mathrm{Hg}$. 

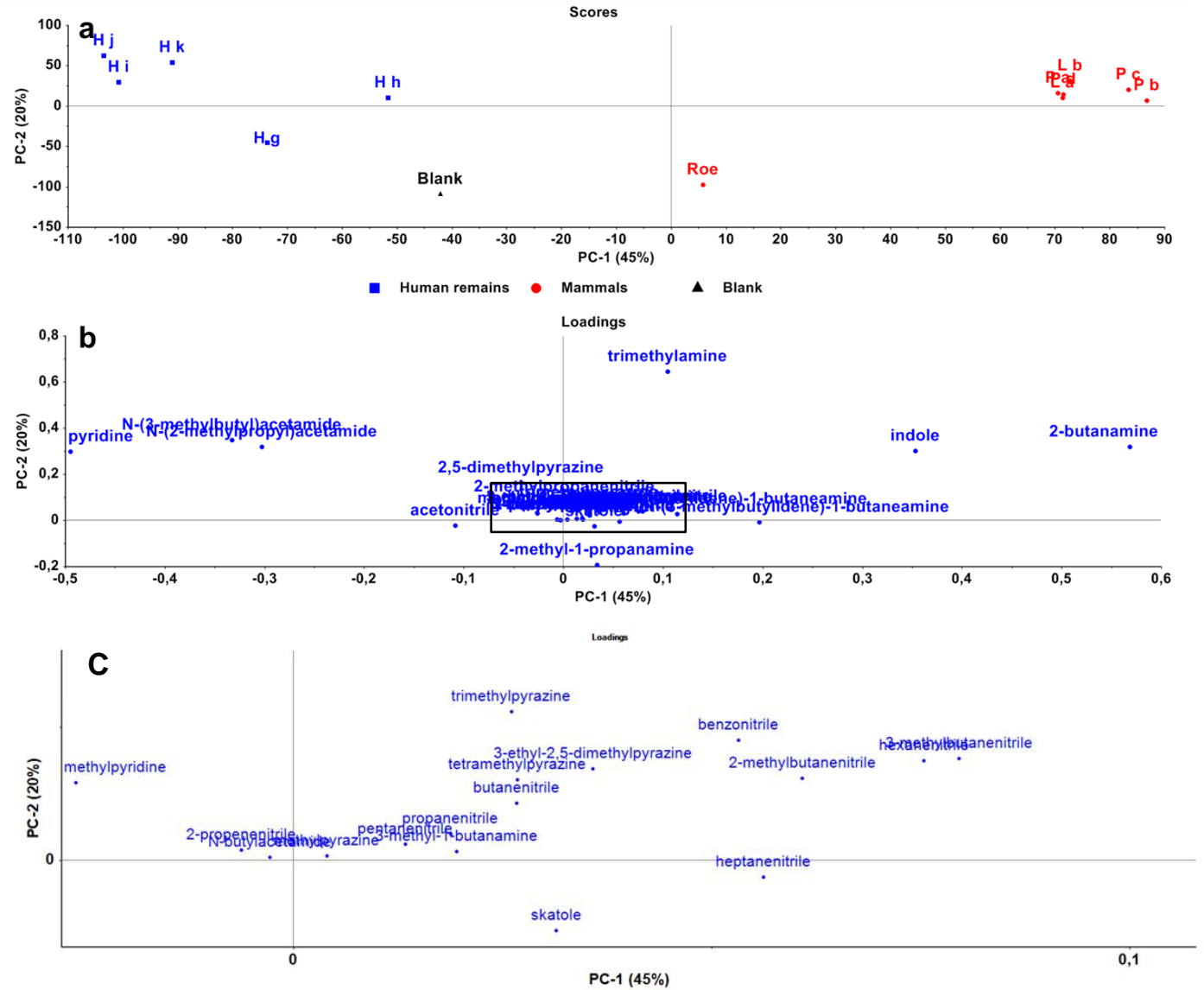

Figure 2: Score- (a), loading-plot (b) of nitrogen-containing compounds and (c) square in detail.

\section{The suggested human and pig specific compounds}

A PCA was conducted on the SIM-results (whenever available, if not full scan data were used) on the VOCs that Rosier et al. suggested as human and pig specific compounds: ethyl propionate, propyl propionate, propyl butyrate, ethyl pentanoate, pyridine, diethyl disulfide, methyl(methylthio)ethyl disulfide and 3-methylthio-1-propanol ${ }^{6}$. In the score-plot, the human remains are situated in the upper right quadrant. Looking at the loading-plot and the frequencies in Table 2, the esters are pulling the animal remains (except for $L b$ ) to the left side of the plot. The human remains are pulled to the upper part since the frequency of pyridine is much higher in these remains. 

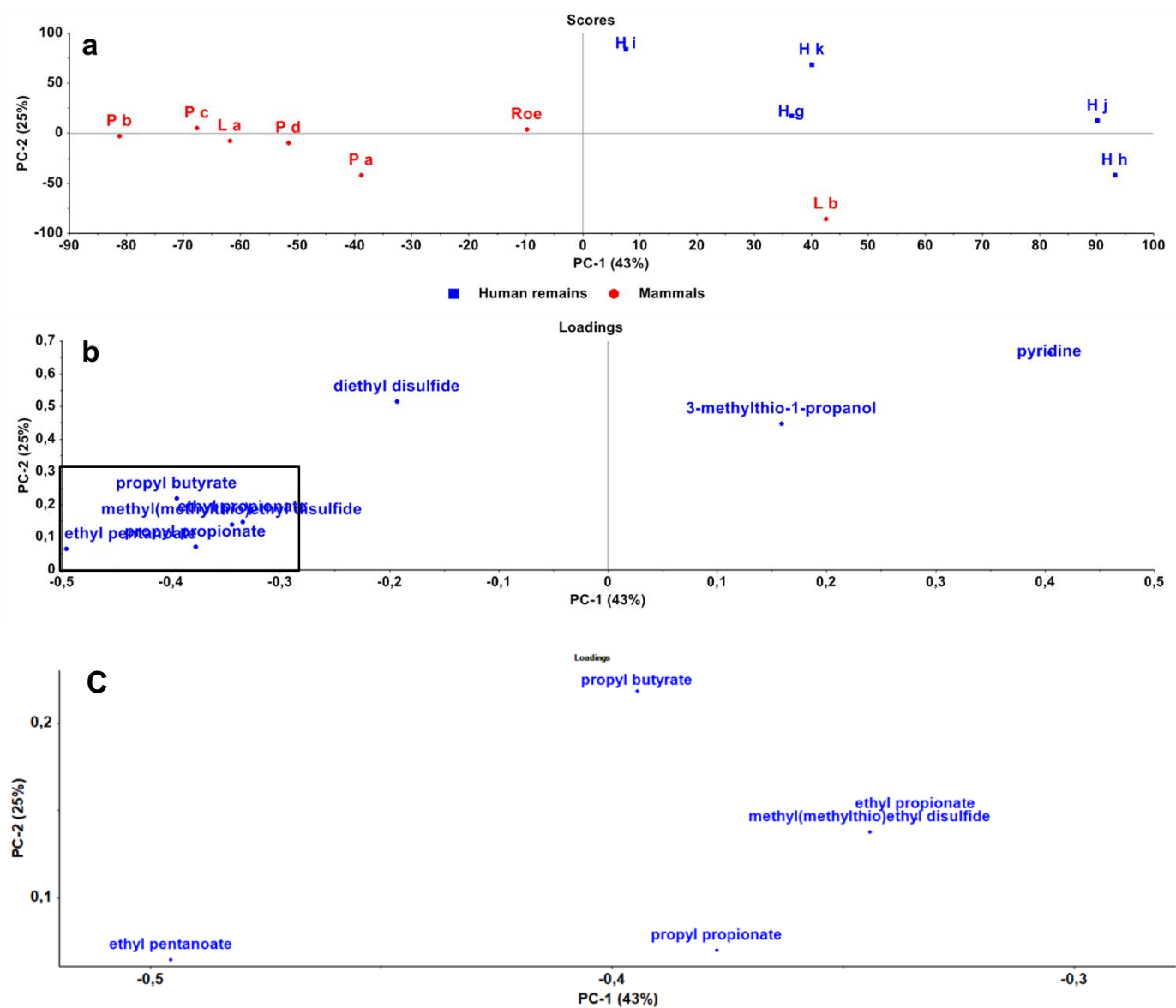

Figure 3: Score- (a) and loading-plot (b) of suggested human and pig specific compounds and (c) square in detail.

Table 2: Frequency of identified suggested human and pig specific compounds in samples. white: $0 \%$, hatched: 0-25\%, light gray: 25-50\%, dark gray: 50-75\% and black: >75 \%. FS-data used for $\mathrm{Hg}, \mathrm{Hh}$ and Roe before day 187, 169 and 18 respectively. $\mathrm{H}$ : human remains, $\mathrm{P}$ : pig remains and L: lamb remains.

\begin{tabular}{lcccccccccccc}
\hline & $\mathbf{H ~ g}$ & $\mathbf{H ~ h}$ & $\mathbf{H ~ i}$ & $\mathbf{H ~ j}$ & $\mathbf{H ~ k}$ & $\mathbf{P ~ a}$ & $\mathbf{P ~ b}$ & $\mathbf{P ~ c}$ & $\mathbf{P ~ d}$ & $\mathbf{L ~ a}$ & $\mathbf{L ~ b}$ & $\mathbf{R o e}$ \\
\hline Ethyl propionate & 100 & 32 & 45 & 26 & 48 & 46 & 96 & 88 & 71 & 92 & 18 & 96 \\
Pyridine & 100 & 52 & 100 & 100 & 100 & 4 & 8 & 38 & 17 & 21 & 5 & 35 \\
Propyl propionate & 26 & 28 & 59 & 43 & 57 & 79 & 96 & 88 & 79 & 96 & 27 \\
Propyl butyrate & 65 & 12 & 91 & 57 & 65 & 96 & 96 & 96 & 96 & 96 & 36 \\
Ethyl pentanoate & 4 & 16 & 59 & 13 & 30 & 67 & 92 & 88 & 58 & 92 & 18 & 91 \\
Diethyl disulfide & 13 & 0 & 95 & 0 & 83 & 33 & 46 & 58 & 58 & 0 & 5 & 39 \\
3-methylthio-1-propanol & 35 & 64 & 91 & 87 & 91 & 21 & 54 & 21 & 29 & 79 & 9 & 65 \\
Methyl(methylthio)ethyl disulfide & 100 & 8 & 73 & 26 & 57 & 58 & 92 & 88 & 88 & 92 & 55 & 83 \\
\hline
\end{tabular}

\section{The suggested pig specific compounds}

In Rosier et al., 5 esters were proposed to be specific for pigs, however only one pig was included in the tests ${ }^{6}$. In this study, a higher number of pig remains was tested to corroborate these results. Therefore, a PCA was performed on these 5 esters. 3-methylbutyl pentanoate was not detected in any of the 
species. In Fig. 4, the pig remains are not separated from human remains, roe and lamb remains. When using more pig remains in the study, the 5 suggested esters were not specific for pig remains.

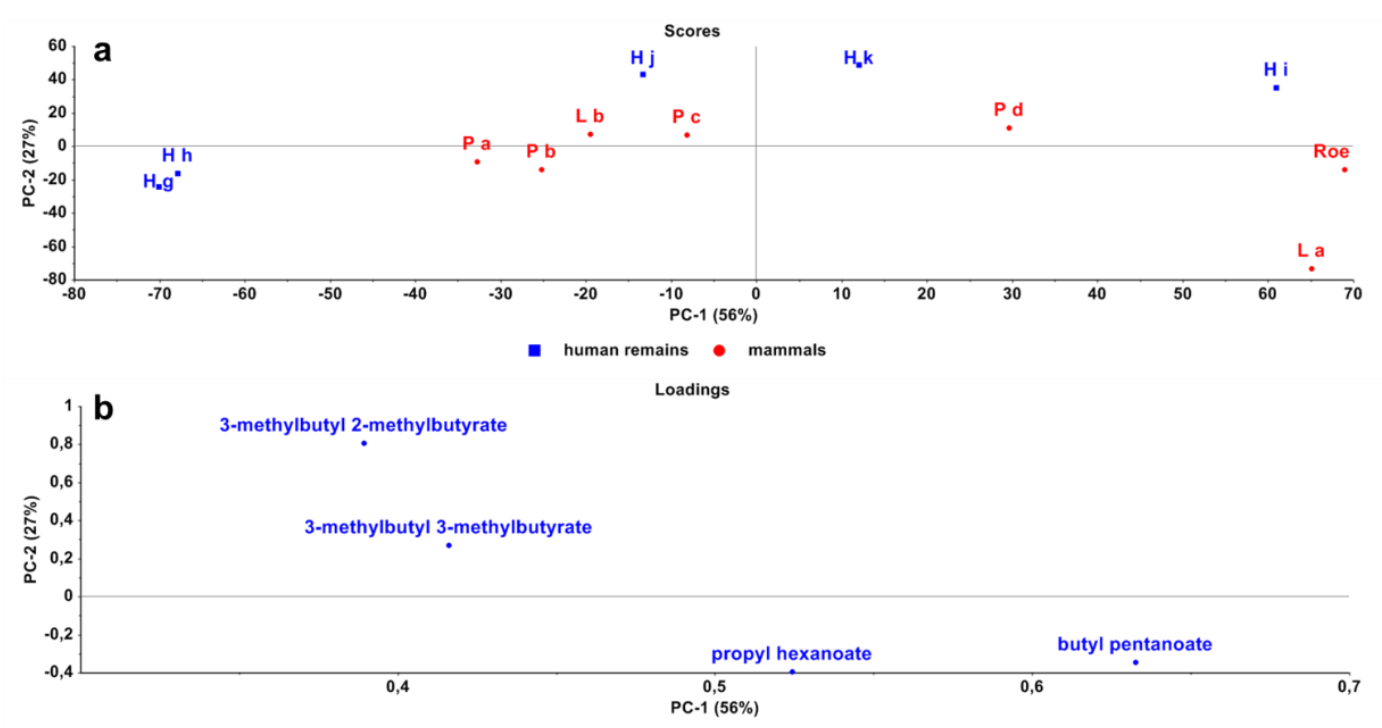

Figure 4: Score- (a) and loading-plot (b) of suggested pig specific compounds. SIM-data were used whenever available for 3-methylbutyl 3-methylbutyrate, propyl hexanoate and butyl pentanoate. 3methylbutyl 2-methylbutyrate was only seen in FS-data.

\section{New proposed human specific mixture}

To separate human remains from animal remains, all previously mentioned results were combined. A PCA was conducted on the combination of the 8 previously published suggested human and pig remains (esters, sulfur-containing compounds and pyridine) and the 5 new identified suggested VOCs that separated the human from the pig, lamb and roe remains (alkanes and acetamides). This PCA was conducted on the results from the human and animal remains from Rosier et al. and the results from this study (human, pig, lamb and roe remains). In Fig. 5, a separation of human remains can be seen. The human remains are pulled to the right, together with pig, lamb and roe remains, based on the 8 previously proposed compounds, and to the upper quadrant by octane, hexane, heptane and pyridine. 

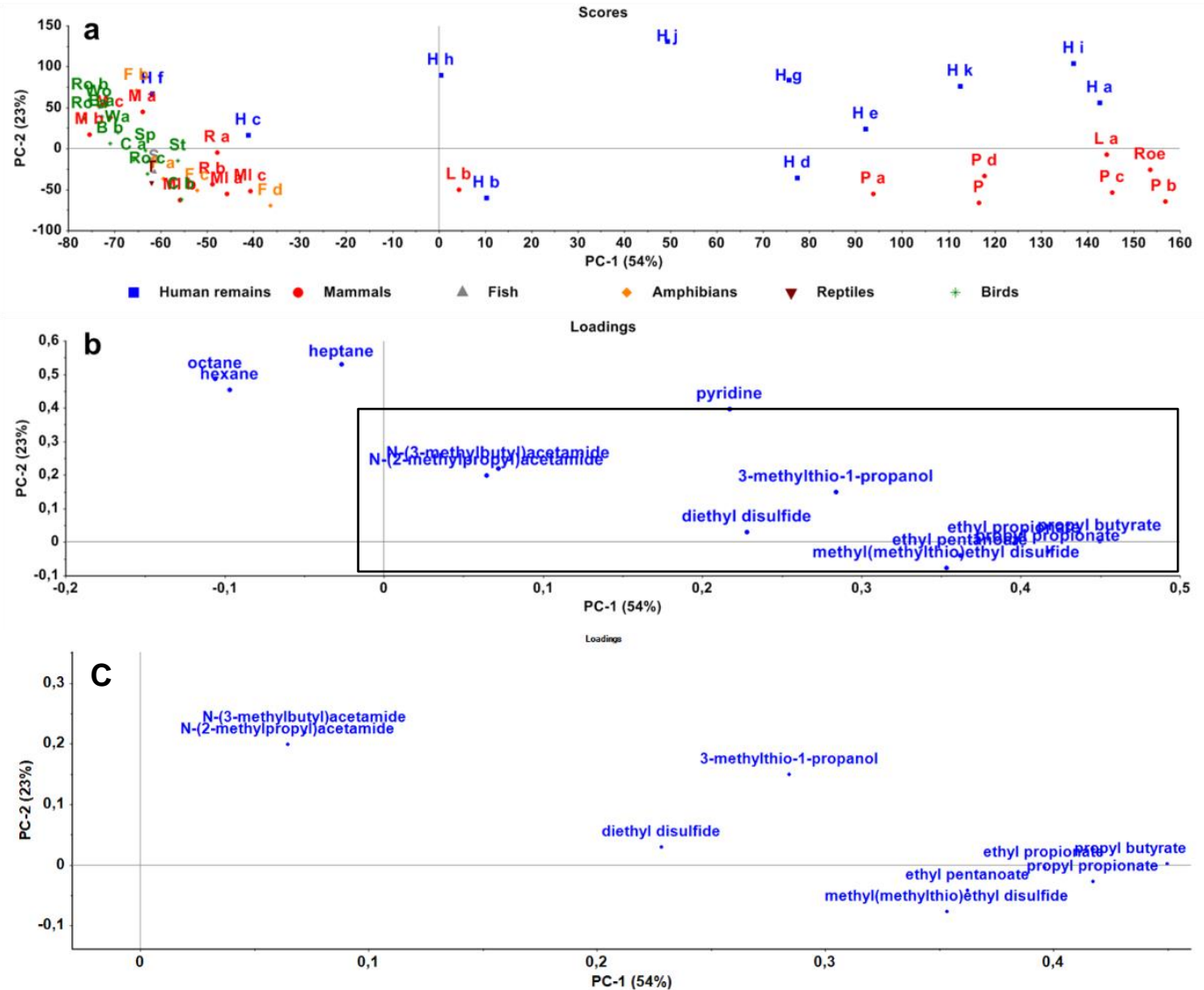

Figure 5: Score (a) and loading plot (b) of human specific combination on all the species and (c) square in detail. Human remains $(H)$, pig remains $(P)$, lamb remains $(L)$, rabbits $(R)$, mice $(M)$, moles $(M I)$,sturgeon (S), frogs (F), turtle (T), chicks (C), robins (Ro), song thrush (St), woodpecker (Wo), warbler (Wa), sparrow (Sp), unidentified birds (B). Data from Rosier et al. combined with data from this study ${ }^{6}$. 


\section{DISCUSSION}

Our previous study focused on the separation between human and animal remains. In that study, a combination of 8 VOCs was proposed as human and pig specific. However, only one pig and no other bigger mammals were tested in the study. ${ }^{6}$ In this study, the goal was to corroborate these results and to separate human from pig, lamb and roe remains. Unfortunately, the number of lamb and roe remains was still low because of the limited availability.

Three other research groups proposed human specific compounds. 10-12 From these 17 compounds, only 4 were not seen in animal remains in Rosier et al.: pentyl hexanoate, hexyl hexanoate, 2-hexenal and 2-octen-3-ol. ${ }^{6}$ Also in this study, these compounds were not identified. A possible explanation is the different sampling method (solid phase microextraction (SPME)), so these compounds can still be specific for human remains. ${ }^{12}$ In this study, the 8 earlier proposed human and pig specific compounds were also detected in the human and pig remains, which corroborate the results previously published. However, these 8 compounds were also seen in the other bigger mammals: lambs and roe. So it seems that this combination is not specific for human and pig remains, but could help in the separation with other animal remains that were previously tested. To separate the human from the animal remains investigated in this study, more specific compounds should be identified or added to this combination.

Therefore, the suggested pig specific compounds were also investigated in this study. 3-methylbutyl pentanoate was not seen, but the other 4 esters were still seen in the pig remains. However, in the previous study the frequency of butyl pentanoate, propyl hexanoate and 3-methylbutyl 2-methylbutyrate were respectively $52 \%, 68 \%$ and $80 \%$. Comparing with this study, the frequencies are lower in the pig remains $(0-41.67 \%, 0-37.5 \%$ and $0-45.17 \%$ respectively). Furthermore, these esters were also seen in the lamb, roe and human remains. Therefore, there was no separation visible in the PCA conducted on these compounds and it can be concluded that these compounds are not specific for pig remains. Cablk et al. suggested two pig specific compounds: 2-methylhexanoic acid and methylhexanoate. ${ }^{12}$ However, these compounds were not identified in this study, this may be due to different sampling method (SPME), and could therefore not help to separate pig from human remains.

Three alkanes (hexane, heptane and octane) and two more nitrogen-containing compounds ( $\mathrm{N}-(3-$ methylbutyl)acetamide and $\mathrm{N}$-(2-methylpropyl)acetamide) together with pyridine were identified as compounds that could separate the human remains from the tested bigger mammals. This separation 
is visible when a PCA is conducted on the 8 previously identified compounds together with these 5 additional human specific compounds (Fig.6).

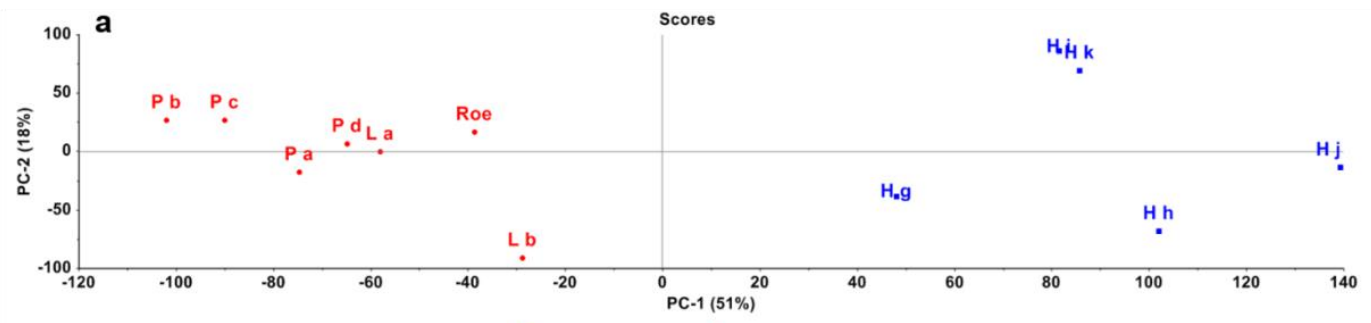

- Human remains - Mammals
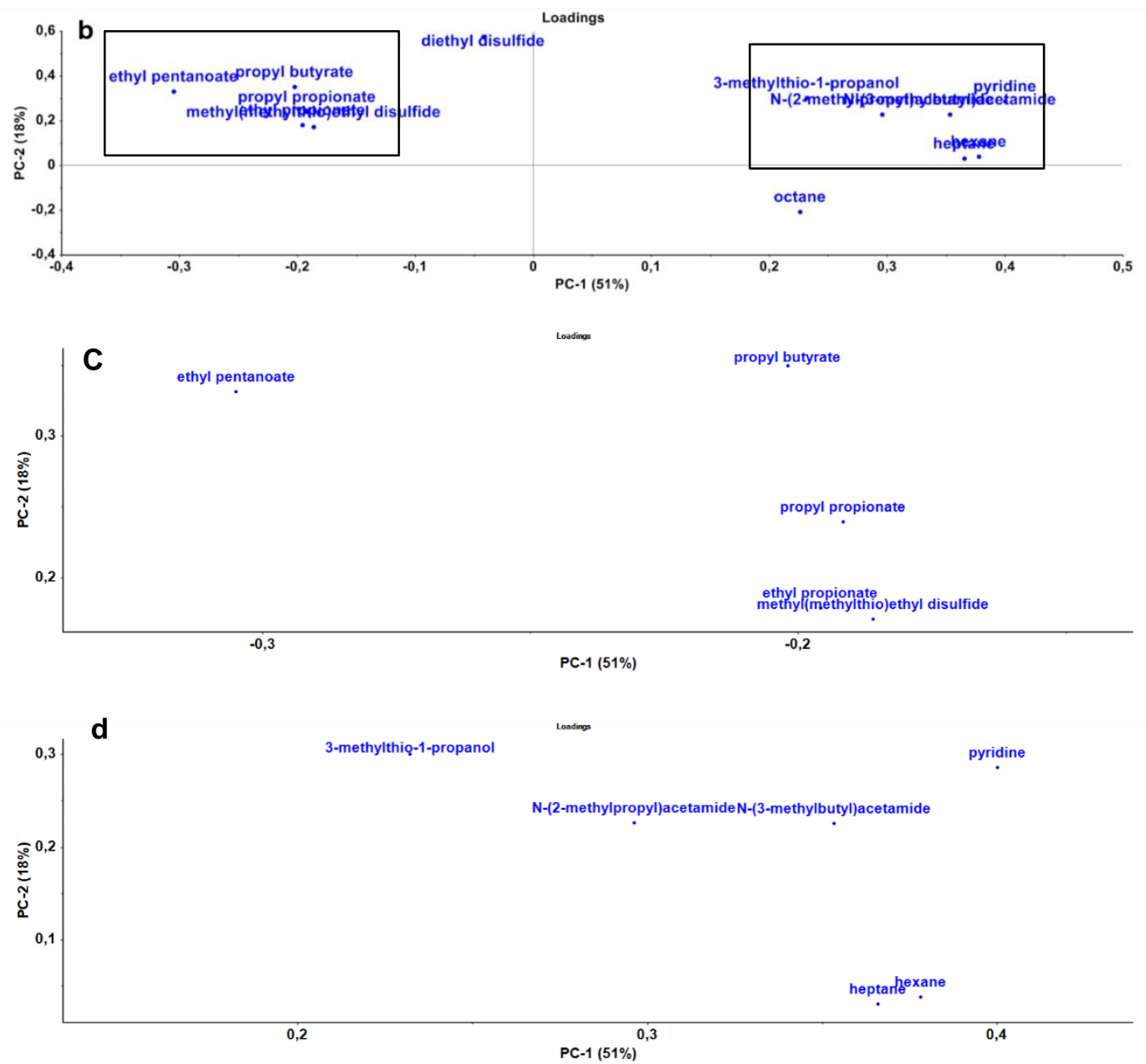

Figure 6: Score- (a) and loading-plot (b) of new proposed human specific combination, (c) and (d) respectively left and right square in detail.

Alkanes can be produced by bacteria from fatty acids. First, the fatty acids are reduced to fatty aldehydes, afterwards, these aldehydes are decarbonylated to alkanes. ${ }^{14-16}$ Hexane, heptane and octane were also identified by other research groups in decomposed human, pig and other animal remains. ${ }^{4-6,8-10,17-24}$ Likewise, these alkanes were detected in Rosier et al. in human remains as well as 
in animal remains such as mice, rabbit, frogs, turtle and different birds. ${ }^{6}$ They were also seen in all the species tested in this study. However, a higher frequency was observed in human remains and therefore these alkanes can possibly be useful in a human specific mix.

Pyridine was found in all human remains at a high frequency, which confirms the results of Rosier et al.. ${ }^{6}$ This compound seems to be specific for human remains. Statheropoulos et al. suggested that pyridine can originate from vitamine B3 (niacine). ${ }^{9}$ However, it remains to be elucidated why pyridine was detected more frequently in human remains. To our knowledge, $\mathrm{N}$-(2-methylpropyl)- and $\mathrm{N}$-(3methylbutyl)acetamide were not seen in previous decomposition studies except in Rosier et al. where these compounds were seen rarely in human, mole, frog and chick remains. These acetamides can be found in cheese and wine, where they are produced by bacteria or yeast. ${ }^{25-27}$

Combining the results from Rosier et al. ${ }^{6}$ and this follow-up study, a combination of 13 compounds seems to be specific for human remains. From these 13 compounds, pyridine is especially interesting since it is seen in very high frequencies in the human remains and practically not in the other animal remains.

In this setup, no full bodies were used and many factors that can influence the decomposition, and therefore perhaps the VOC-profile, were absent. However, a combination of tissue (fat, muscle, liver and intestines) was sampled whenever possible to replicate a full body. Enzymes from liver and bacteria from intestines could start the decomposition. In the laboratory environment, environmental parameters, such as temperature and moisture, could be controlled and a concentrated environment could be generated. Nevertheless, further investigation in the field using full bodies has to corroborate these results. Despite its limits, this study is important in the decomposition research since VOC-profiles of human and different animal remains are compared in the same setup. Using these results, first tests with cadaver dogs can be conducted to verify if (1) cadaver dogs respond on this mixture of compounds showing they recognize the mixture as decomposing remains. There is still not much known about which compounds trigger the dogs. (2) If canines can be trained with this synthetic mixture and link it with the odor of human decomposition remains. Another approach would be to use these results to develop portable analytical detectors to search for human remains. Further investigation is needed here. 


\section{CONCLUSIONS}

In this study, the VOC-profiles of 5 decomposed human remains were compared with remains of 4 pigs, 2 lambs and 1 roe. The VOCs were analyzed using a TD-GC/MS. To separate the human from the animal remains, it seems that the previously suggested 8 compounds (ethyl propionate, propyl propionate, propyl butyrate, ethyl pentanoate, pyridine, diethyl disulfide, 3-methytlhio-1-propanol and methyl(methylthio)ethyl disulfide) have to be combined with some new identified specific VOCs. Hexane, heptane, octane, N-(3-methylbutyl)- and N-(2-methylpropyl)acetamide could separate the human remains from the other analyzed mammals. Especially pyridine seems to be very interesting as a human specific marker. Such human specific markers can be used to train cadaver dogs more efficiently or develop detector to locate human remains. Although this study is valuable in the decomposition research, these results still have to be verified in the field using full bodies. 


\section{REFERENCES}

1. DeGreeff LE, Weakley-Jones B, Furton KG. Creation of training aids for human remains detection canines utilizing a non-contact, dynamic airflow volatile concentration technique. Forensic Sci Int. 2012 Apr 10;217(1-3):32-8. PubMed PMID: 22018852.

2. Swann LF, SL; Lewis, SW. Analytical separations of mammalian decomposition products for forensic science: a review. Analytica Chimica Acta. 2010;682:9-22.

3. Schultz JJ. Sequential monitoring of burials containing small pig cadavers using ground penetrating radar. J Forensic Sci. 2008 Mar;53(2):279-87. PubMed PMID: 18366561.

4. Dekeirsschieter J, Stefanuto PH, Brasseur C, Haubruge E, Focant JF. Enhanced characterization of the smell of death by comprehensive two-dimensional gas chromatography-time-offlight mass spectrometry (GCxGC-TOFMS). PLoS One. 2012;7(6):e39005. PubMed PMID: 22723918. Pubmed Central PMCID: 3377612.

5. Perrault KA, Stefanuto PH, Stuart BH, Rai T, Focant JF, Forbes SL. Detection of decomposition volatile organic compounds in soil following removal of remains from a surface deposition site. Forensic science, medicine, and pathology. 2015 Sep;11(3):376-87. PubMed PMID: 26227510.

6. Rosier E, Loix S, Develter W, Van de Voorde W, Tytgat J, Cuypers E. The Search for a Volatile Human Specific Marker in the Decomposition Process. PLoS One. 2015;10(9):e0137341. PubMed PMID: 26375029. Pubmed Central PMCID: 4572707.

7. Brasseur C, Dekeirsschieter J, Schotsmans EM, de Koning S, Wilson AS, Haubruge E, et al. Comprehensive two-dimensional gas chromatography-time-of-flight mass spectrometry for the forensic study of cadaveric volatile organic compounds released in soil by buried decaying pig carcasses. Journal of chromatography A. 2012 Sep 14;1255:163-70. PubMed PMID: 22520639.

8. Forbes SL, Perrault KA. Decomposition odour profiling in the air and soil surrounding vertebrate carrion. PLoS One. 2014;9(4):e95107. PubMed PMID: 24740412. Pubmed Central PMCID: 3989314.

9. Statheropoulos M, Agapiou A, Zorba E, Mikedi K, Karma S, Pallis GC, et al. Combined chemical and optical methods for monitoring the early decay stages of surrogate human models. Forensic Sci Int. 2011 Jul 15;210(1-3):154-63. PubMed PMID: 21450424.

10. Vass AA. Odor mortis. Forensic Sci Int. 2012 Oct 10;222(1-3):234-41. PubMed PMID: 22727573.

11. DeGreeff LE, Furton KG. Collection and identification of human remains volatiles by noncontact, dynamic airflow sampling and SPME-GC/MS using various sorbent materials. Anal Bioanal Chem. 2011 Sep;401(4):1295-307. PubMed PMID: 21695377. eng.

12. Cablk ME, Szelagowski EE, Sagebiel JC. Characterization of the volatile organic compounds present in the headspace of decomposing animal remains, and compared with human remains. Forensic Sci Int. 2012 Jul 10;220(1-3):118-25. PubMed PMID: 22424672.

13. Stadler S, Stefanuto PH, Byer JD, Brokl M, Forbes S, Focant JF. Analysis of synthetic canine training aids by comprehensive two-dimensional gas chromatography-time of flight mass spectrometry. Journal of chromatography A. 2012 Sep 14;1255:202-6. PubMed PMID: 22554412.

14. Park MO. New pathway for long-chain $\mathrm{n}$-alkane synthesis via 1-alcohol in Vibrio furnissii M1. J Bacteriol. 2005 Feb;187(4):1426-9. PubMed PMID: 15687207. Pubmed Central PMCID: 545631.

15. Wang W, Lu X. Microbial Synthesis of Alka(e)nes. Frontiers in bioengineering and biotechnology. 2013;1:10. PubMed PMID: 25023719. Pubmed Central PMCID: 4090904.

16. Paczkowski S, Schutz S. Post-mortem volatiles of vertebrate tissue. Appl Microbiol Biotechnol. 2011 Aug;91(4):917-35. PubMed PMID: 21720824. Pubmed Central PMCID: 3145088.

17. Forbes SL, Perrault KA, Stefanuto PH, Nizio KD, Focant JF. Comparison of the decomposition VOC profile during winter and summer in a moist, mid-latitude (Cfb) climate. PLoS One. 2014;9(11):e113681. PubMed PMID: 25412504. Pubmed Central PMCID: 4239107.

18. Perrault KA, Rai T, Stuart BH, Forbes SL. Seasonal comparison of carrion volatiles in decomposition soil using comprehensive two-dimensional gas chromatography - time of flight mass spectrometry. Anal Methods. 2015;7:690-8.

19. Perrault KA, Stefanuto PH, Stuart BH, Rai T, Focant JF, Forbes SL. Reducing variation in decomposition odour profiling using comprehensive two-dimensional gas chromatography. Journal of separation science. 2015 Jan;38(1):73-80. PubMed PMID: 25353389.

20. Vass AA, Smith RR, Thompson CV, Burnett MN, Dulgerian N, Eckenrode BA. Odor analysis of decomposing buried human remains. J Forensic Sci. 2008 Mar;53(2):384-91. PubMed PMID: 18366571. eng.

21. Vass AA, Smith RR, Thompson CV, Burnett MN, Wolf DA, Synstelien JA, et al. Decompositional odor analysis database. J Forensic Sci. 2004 Jul;49(4):760-9. PubMed PMID: 15317191. eng. 
22. Statheropoulos M, Agapiou A, Spiliopoulou C, Pallis GC, Sianos E. Environmental aspects of VOCs evolved in the early stages of human decomposition. Sci Total Environ. 2007 Oct 15;385(13):221-7. PubMed PMID: 17669473. eng.

23. Statheropoulos M, Spiliopoulou C, Agapiou A. A study of volatile organic compounds evolved from the decaying human body. Forensic Sci Int. 2005 Oct 29;153(2-3):147-55. PubMed PMID: 16139103. eng.

24. Stadler S, Stefanuto PH, BrokI M, Forbes SL, Focant JF. Characterization of volatile organic compounds from human analogue decomposition using thermal desorption coupled to comprehensive two-dimensional gas chromatography-time-of-flight mass spectrometry. Analytical chemistry. 2013 Jan 15;85(2):998-1005. PubMed PMID: 23215054.

25. Adda L, Gripon JC, Vassal L. The Chemistry of Flavor and Texture Generation in Cheese. Food Chemistry. 1982;9(1-2):115-29. PubMed PMID: WOS:A1982PA89000010. English.

26. Urbach $\mathrm{G}$. The flavour of milk and dairy products .2. Cheese: contribution of volatile compounds. Int J Dairy Technol. 1997 Aug;50(3):79-89. PubMed PMID: WOS:A1997YB68000001. English.

27. Campeanu G, Burcea M, Doneanu C, Namolosanu I, Visan L. GC/MS characterization of the volatiles isolated from the wines obtained from the indigenous cultivar Feteasca regala. Analusis. 1998 Mar;26(2):93-7. PubMed PMID: WOS:000072873200017. English. 


\section{FIGURES AND TABLES}

Figures

Figure 1: Score- (a) and loading-plot (b) of alkanes.

Figure 2: Score- (a) and loading-plot (b) of nitrogen-containing compounds.

Figure 3: Score- (a) and loading-plot (b) of suggested human and pig specific compounds.

Figure 4: Score- (a) and loading-plot (b) of suggested pig specific compounds. SIM-data were used whenever available for 3-methylbutyl 3-methylbutyrate, propyl hexanoate and butyl pentanoate. 3methylbutyl 2-methylbutyrate was only seen in FS-data.

Figure 5: Score (a) and loading plot (b) of human specific combination on all the species. Human remains $(H)$, pig remains $(P)$, lamb remains $(L)$, rabbits $(R)$, mice $(M)$, moles $(M I)$,sturgeon $(S)$, frogs $(F)$, turtle $(T)$, chicks (C), robins (Ro), song thrush (St), woodpecker (Wo), warbler (Wa), sparrow (Sp), unidentified birds $(B)$. Data from Rosier et al. combined with data from this study ${ }^{6}$.

Figure 6: Score- (a) and loading-plot (b) of new proposed human specific combination.

$\underline{\text { Tables }}$

Table 1: SIM-ions of suggested human and pig specific compounds.

Table 2: Frequency of identified suggested human and pig specific compounds in samples. white: $0 \%$, hatched: 0-25\%, light gray: 25-50\%, dark gray: 50-75\% and black: >75 \%. FS-data used for $\mathrm{Hg}, \mathrm{H} \mathrm{h}$ and Roe before day 187, 169 and 18 respectively. H: human remains, P: pig remains and L: lamb remains. 